\title{
Perbandingan Peningkatan Kuat Tekan Beton Normal Dengan Menggunakan SNI 03-2834-2000 dan SNI 7656:2012 Sampai Umur 28 Hari
}

\author{
Ivan Setiawan, Suhendra*, Ria Zulfiati \\ Program Studi Teknik Sipil Universitas Batanghari Jambi \\ *Correspondence email: suhendra_domas@yahoo.com
}

\begin{abstract}
Abstrak. Awal mula terbentuk SNI 7656:2012, rancangan campuran beton normal berpedoman sesuai SNI 03-2834-2000. Untuk riset sekarang sudah dicoba sesuatu perbandingan rancangan kepada kedua SNI bersangkutan untuk kualitas beton 25 MPa. Benda uji dipakai berupa silinder dengan dimensi 150milimeter x 300milimeter, berjumlah 15 benda uji buat tiap- tiap SNI. Penyelesaian riset menampilkan mutu yang diperoleh SNI 2000 dan SNI 2012 berturut: 21,95 MPa dan 23,01 MPa. Berikutnya, nilai slump buat kedua rancangan beton adalah 70 milimeter. Penyelesaian ini menampilkan kalau hasil nilai mutu yang dihasilkan dari rancangan campuran sesuai SNI 2000 sangat besar dibandingkan nilai mutu SNI 2012 dan keduanya memperlihatkan nilai slump yang bagus. Keduanya SNI memperlihatkan ikatan empiris dan relative dari kepada bahan beton didalam campuran, berdasarkan rancangan kandungan bahan yang diperoleh tiap -tiap tata cara hendak berbeda-beda, yang disetiap ujungnya bakal mendapatkan nilai mutu yang beda-beda.
\end{abstract}

Kata Kunci : campuran beton, kuat tekan, beton normal

\section{PENDAHULUAN}

Pembangunan bidang struktur hadapi perkembangan yang cepat, berlangsung disetiap bidang, contohnya bangunan gedung, jembatan, menara dan lainnya. Beton ialah opsi selaku bahan struktur pada konstruksi bangunan. Beton disukai sebab banyak mempunyai kelebihan dibanding bahan yang lain, memiliki power yang bagus, bahan baku penyusun gampang ditemukan, tahan usang, tahan api, tidak hadapi pembauan. Ide teknologi beton senantiasa diharuskan manfaat menanggapi rintangan hendak kebutuhan, beton yang diperoleh diwajibkan memiliki mutu besar seperti kekuatan serta energi tahan tanpa menghiraukan nilai murah.

Seorang perencana beton wajib bisa merancang campuran beton yanng sesuai standar ekonomi serta kualifikasi teknis. sekarang ada beberapa metode rancang campuran beton yang ada diindonesia, sehingga pada riset ini akan membandingkan tiap-tiap metode rancang campur beton yang sampai saat ini berlaku diIndonesia.

Untuk menentukan mutu kuat tekan beton, jadi riset dikerjakan pada usia 28 day. Akhirnya muncul kendala, ternyata kita mengharapkan nilai yanng efisien agar memperoleh hasil kuat beton tercapai atau tidaknya karna berbagai faktor.Maka dari itu perlunya dilakukan pengujian kuat tekan beton dibawah 28 hari sesuai dengan PBI agar bisa mengetahui hasil mutu beton ketika 28 hari mecapai nilai yang dikehendaki atau tidaknya. Didalam PBI dimuat ada faktor usia beton ke usia uji 28 day. Mengenai faktor tertera adalah ketika Usia 3 day 0,40 Usia 7 day 0,65 Usia 14 day 0,88 Usia 21 day 0,95 dan memasuki Usia 28 day adalah 1.

Dalam perancangan campuran beton sebelumnya dibuat pengetesan kepada material penataan yang dipakai, untuk menghasilkan data agregat yang mungkin agregat bisa dipakai atau tidak serta pada data material yang digunakan dilaksanakan penaksiran perhitungan campuran (mix design), yang kemudian dapat dihasilkan keperluan agregat yaitu perbandingan berat serta perbandingan kapasitas yang bisa dipakai suatu cara pencampuran beton. Pada jalur hitungan rancangan campuran beton tiap-tiap metode yang merupakan dalam negeri ataupun luar negeri, bagi metode rancangan campuran beton diIndonesia, berlaku standar desain campuran beton dari SNI 03-2834-1993, SNI 03-2834-2000, SNI 03-3449-2002 dan yang terkini SNI 7656:2012. Yang ialah pedoman yang dipakai pada peraturan desain campuran beton diIndonesia yaitu SNI 03-2834-2000 berpedoman pada DOE 19750 dan SNI 7656:2012 yang berpedoman dengan ACI 211.1-91.

Pada tinjauan ini, ulasan biaya dan mutu dikerjakan sesuai perhitungan campur beton normal (Mix Design) SNI 03-2834-2000 dan SNI 7656:2012 sebab kedua SNI berfungsi untuk acuan perhitungan campur beton diIndonesia. Sehingga membandingkan kedua SNI diinginkan supaya memperoleh perhitungan campuran yang sangat murah dengan f'c sesuai diinginkan.

\section{Tinjauan Pustaka}

\section{Rancangan campuran beton}

Beton dijelaskan menjadi suatu campuran berdasarkan empat bahan dasar tersendiri, ialah: semen, agregat kasar, agregat halus, dan air. Menurut definisi lain, beton bisa dijelaskan untuk campuran bergradasi pada agregat halus dan agregat kasar yang ditempelkan bersamaan dengan pasta semen (Kett, I, 2010). 
Rancangan campuran beton ditunjukan supaya mengetahui campuran yang sangat ekonomis dan praktis ketersedian bahan lokal, dapat tercapai kemudahan kerja (workablity) yang diinginkan pada situasi plastis dan akan memenuhi persyaratan saat keras (Day, K., W., 2006).

Beberapa keputusan harus wajib memenuhi pada campuran beton, yaitu: ketahanan, durabilitas, impermeabilitas, kesederhanaan kerja (workability), stabilitas ukuran, berprilaku bagus serta ekonomis (Day, K., W., 2006).

\section{Prosedur Rancangan Campuran}

\section{Prosedur SNI 03-2834-2000}

Tata cara merancang metode SNI 2000, mengambil sebagian pendapat sebagai berikut:

a. Mode berikut hanya diperuntukan Ordinary Portland Cement (tipe I), Rapid- Hardening Portland Cement (tipe II), High Early Strength Cement (tipe III) serta Sulphate Resisting Portland Cement (tipe V);

b. Mode berikut mengelompokan untuk agregat pecah (batu pecah) serta tidak dipecah (agregatalami/kerikil) yaang dapat merubah kapasitas pemakaian air;

c. Menaksir gradasi suatu agregat halus sesuai daerah serta beranggapan gradasi yang agregat halus bisa merubah suatu kekuatan kinerja pada campuran beton;

d. Proporsi optimal suatu kapasitas curah agregat kasar per kubik beton mengikuti untuk ukuran maksiimum nomiinal pada agregat kasar serta gradasi agregat halus;

e. Ukuran air suatu campuran beton bisa disesuaikan dengan skala kesederhanaan work dibutuhkan, diperoleh berdasarkan ujislump atau uji $\mathrm{VeBe}$;

f. Kadar maksiimum nomiinal suatu agregat kasar, dinyatakan tidak merubah jumlah campuran;

g. Mode mengambil campuran beton hipotesis dengan rasio air semen (fas) 0,5 .

\section{Prosedur SNI 7656:2012}

Tata cara merancang metode SNI 2012, mengambil sebagian pendapat yaitu:

a. Metode berikut tidak bedakan merk semen hidrolik (diperuntukan berbagai merk semen hidrolik) serta macam agregat;

b. Kestabilan campuran bisa menyesuaikan kesederhanaan work diperlakukan cuma mengikuti dari kapasitas air bebas pada proporsi campuran, dinampakan sesuai uji slump, uji VeBe atau uji faktor pemampatan;

c. Skala ideal pada kapasitas curah agregat kasar per kubik beton bergantung kepada dimensi teratas nominal agregat kasar serta gradasi agregat halus;

d. macam pemampatan berefek pada ukuran slump disarankan;

e. waktu yang ditentukan banyaknya bahan campuran beton bisa dikerjakan sesuai ekivalensi bobot ataupun ekivalensi banyak absolut.

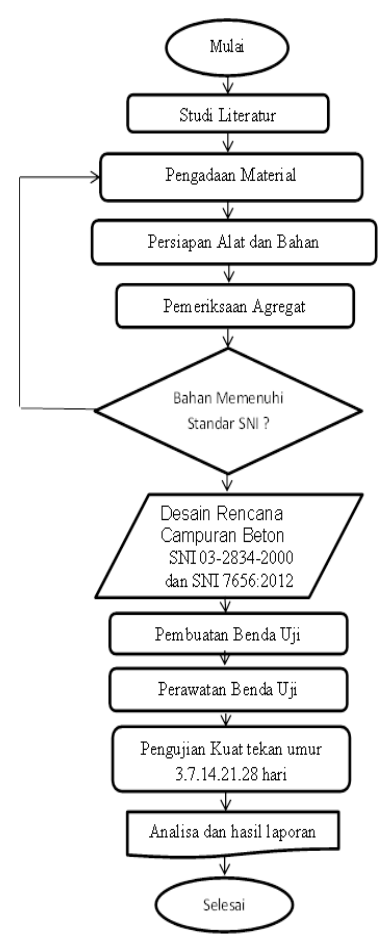

Gambar 1 Diagram Rancangan Campuran Beton 
Ivan Setiawan, Suhendra dan Ria Zulfiati, Perbandingan Peningkatan Kuat Tekan Beton Normal Dengan Menggunakan SNI 03-2834-2000 dan SNI 7656:2012 Sampai Umur 28 Hari

\section{METODE}

\section{Skala Rancangan}

Material yang dipakai kajian ini adalah semen portland tipe I Tiga Roda. Pasir yang digunakan berasal dari Sungai Rengas Bandung ex.Batanghari, Batu Pecah berasal dari Merak \& Bojonegara dan Air adukan beton dari PDAM Tirta Mayang

Data material peroleh pengamatan laboratorium serta parameter lainnya bisa dipakai pada rancangan beton ditunjukan pada Tabel yaitu:

Tabel 1 Skala rancangan campuran beton

\begin{tabular}{|c|c|c|c|}
\hline No & \multicolumn{2}{|l|}{ Skala } & Data \\
\hline 1 & \multicolumn{2}{|l|}{ Mutu rencana, f'c (MPa) } & 20 \\
\hline 2 & \multicolumn{2}{|l|}{ Jenis semen } & $\begin{array}{c}\text { Semen Portland, } \\
\text { tipe I }\end{array}$ \\
\hline 3 & \multicolumn{2}{|l|}{$\begin{array}{c}\text { Dimensi maks nomin } \\
\text { agregat kasar }(\mathrm{mm})\end{array}$} & 19 \\
\hline 4 & \multicolumn{2}{|l|}{ Macam agregat halus } & Pasir \\
\hline \multirow[t]{2}{*}{5} & \multirow[t]{2}{*}{ Macam agregat kasar } & Semen $\downarrow$ & $\begin{array}{c}\text { Batu Pecah } \\
\quad 3,15\end{array}$ \\
\hline & & Pasir (SSD) & 2,604 \\
\hline 6 & Bobot jenis & Kerikil (SSD) & 2,589 \\
\hline \multirow[t]{2}{*}{7} & \multirow[t]{2}{*}{ Berat volume $\left(\mathrm{Kg} / \mathrm{m}^{3}\right)$} & Pasir $\Downarrow$ & 1584 \\
\hline & & Kerikil & 1345 \\
\hline \multirow[t]{2}{*}{8} & \multirow[t]{2}{*}{ Modulus halus butir } & Pasir & 2,83 \\
\hline & & Kerikil & 7,56 \\
\hline \multirow[t]{2}{*}{9} & \multirow[t]{2}{*}{ Kadar kelembaban (\%) } & Pasir & 5 \\
\hline & & Kerikil & 1,67 \\
\hline \multirow[t]{2}{*}{10} & \multirow{2}{*}{\multicolumn{2}{|c|}{ Slump rencana $(\mathrm{mm})$}} & $60-180$ \\
\hline & & & $75-100$ \\
\hline 11 & \multicolumn{2}{|l|}{ Bahan tambah kimia } & - \\
\hline
\end{tabular}

Sumber: Olahan Data (2020)

\section{Jumlah Benda Uji}

Tiap-tiap benda uji tiap metode dipakai 3 benda uji disetiap hari waktu pengujian kuat tekan.Berikut tabel banyaknya benda uji :

Tabel 2 Jumlah Benda Uji

\begin{tabular}{lcccccc}
\hline \multicolumn{1}{c}{ Metode } & 3 & 7 & 14 & 21 & 28 & Total \\
\hline SNI 03 - 2834-2000 & 3 & 3 & 3 & 3 & 3 & 15 \\
SNI 7656:2012 & 3 & 3 & 3 & 3 & 3 & 15 \\
\hline \multicolumn{7}{c}{ Total } \\
\hline
\end{tabular}

Sumber : Olahan Data (2020)

\section{Penguraian Pilihan Agregat}

Uraian pengamatan pilihan kepada agregat halus serta agregat kasar dilihat menggunakan tabel yaitu:

Tabel 3 Penguraian pilihan agregat

\begin{tabular}{ccc}
\hline $\begin{array}{c}\text { Ukuran Saringan } \\
\text { (milimeter) }\end{array}$ & \multicolumn{2}{c}{ \% Lolos Kumulatif } \\
25 milimeter & & Kerikil \\
\hline 19 milimeter & & 100 \\
12,5 milimeter & & 97 \\
9,5 milimeter & & 37 \\
4,75 milimeter & 100 & 7 \\
2,36 milimeter & 90 & 3 \\
1,18 milimeter & 70 & \\
0,6 milimeter & 40 & \\
0,3 milimeter & 12 & \\
0,15 milimeter & 5 & \\
\hline
\end{tabular}

Sumber : Olahan Data (2020) 
Ivan Setiawan, Suhendra dan Ria Zulfiati, Perbandingan Peningkatan Kuat Tekan Beton Normal Dengan Menggunakan SNI 03-2834-2000 dan SNI 7656:2012 Sampai Umur 28 Hari

\section{Pemeriksaan Agregat Halus}

Pelaksanaan pemeriksaan fisik agregat halus yang diteliti dengan riset tugas akhir ini mengacu sesuai dengan SNI pada tiap-tiap parameter uji pemeriksaan agregat halus. Adapun hasilnya sebagai berikut:

Tabel 4 Uraian Pengujian Agregat Halus

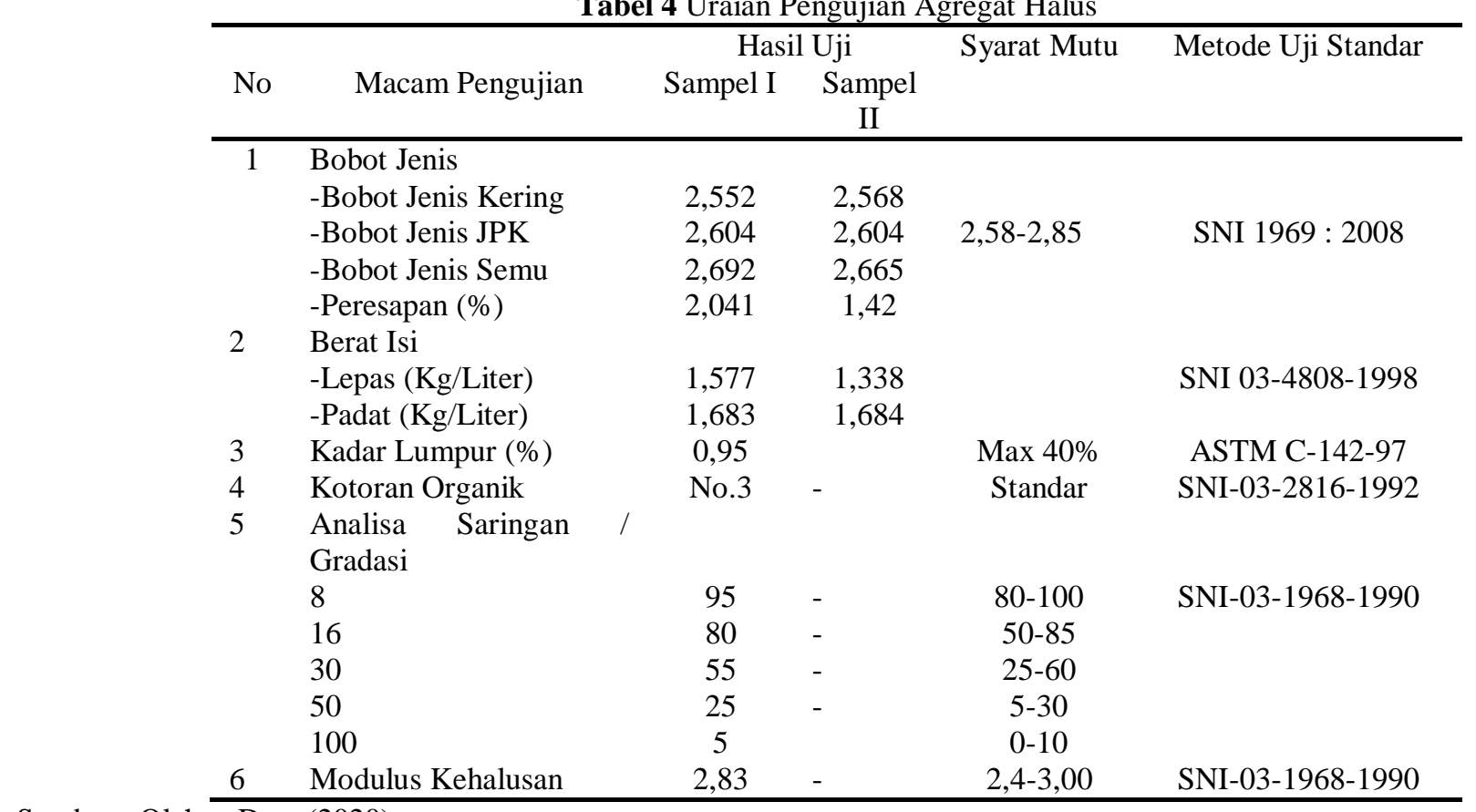

Sumber : Olahan Data (2020)

\section{Pemeriksaan Agregat Kasar (Batu pecah)}

Pelaksanaan pemeriksaan fisik agregat kasar yang diteliti pada riset tugas akhir ini berdasarkan sesuai dengan SNI pada tiap-tiap parameter uji pemeriksaan agregat kasar. Adapun hasil sebagai berikut:

Tabel 5 Pemeriksaan Agregat Kasar

\begin{tabular}{|c|c|c|c|c|c|c|}
\hline \multirow[b]{2}{*}{ No } & \multirow{2}{*}{\multicolumn{2}{|c|}{ Macam Pengujian }} & \multicolumn{2}{|c|}{ Hasil Uji } & \multirow[t]{2}{*}{ Syarat Mutu } & \multirow[t]{2}{*}{ Metode Uji Standar } \\
\hline & & & Sampel I & $\begin{array}{l}\text { Sampel } \\
\text { II }\end{array}$ & & \\
\hline \multirow[t]{5}{*}{1} & \multicolumn{6}{|l|}{ Bobot Jenis } \\
\hline & \multicolumn{2}{|l|}{-Bobot Jenis Kering } & 2,582 & 2,536 & & \\
\hline & \multicolumn{2}{|l|}{-Bobot Jenis JPK } & 2,603 & 2,574 & $2,58-2,85$ & SNI 1969:2008 \\
\hline & \multicolumn{2}{|l|}{-Bobot Jenis Semu } & 2,639 & 2,635 & & \\
\hline & \multicolumn{2}{|l|}{-Peresapan $(\%)$} & 0,842 & 1,48 & & \\
\hline \multirow[t]{3}{*}{2} & \multicolumn{6}{|l|}{ Berat Isi } \\
\hline & \multirow{2}{*}{\multicolumn{2}{|c|}{$\begin{array}{l}\text {-Lepas / Gembur (Kg/Liter) } \\
\text {-Padat (Kg/Liter) }\end{array}$}} & 1,351 & 1,338 & & SNI 03-4808-1998 \\
\hline & & & 1,42 & 1,41 & & \\
\hline \multirow[t]{2}{*}{3} & \multirow{2}{*}{\multicolumn{2}{|c|}{$\begin{array}{l}\text { Ketahanan Agregat } \\
\text { Keausan / Abrasi Test }\end{array}$}} & & & $\operatorname{Max} 40 \%$ & \\
\hline & & & 24,20 & 25,58 & & SNI 2417:2008 \\
\hline \multirow[t]{2}{*}{4} & \multirow{2}{*}{\multicolumn{2}{|c|}{ Benturan / Impact Test }} & & & & SNI 03-1757-1990 \\
\hline & & & 16,50 & 17,48 & $10-20 \%$ & \\
\hline 5 & $\begin{array}{l}\text { Ketahanan Agregat } \\
\text { Tekanan }\end{array}$ & terhadap & 25,2 & & & SNI 03-1757-1990 \\
\hline 6 & Kadar Lumpur (\%) & & 2,95 & - & $\operatorname{Max} 1 \%$ & ASTM C-142-97 \\
\hline \multirow[t]{6}{*}{7} & \multicolumn{6}{|l|}{$\begin{array}{l}\text { Analisa Saringan / Gradasi } \\
1\end{array}$} \\
\hline & $3 / 4$ & & 100 & - & 100 & \\
\hline & $1 / 2$ & & 97 & - & $90-100$ & \\
\hline & $3 / 8$ & & 37 & - & $20-55$ & ASTM C33-03 \\
\hline & 4 & & 7 & - & $0-15$ & \\
\hline & & & 3 & - & $0-5$ & \\
\hline 8 & Modulus Kehalusan & & 7,56 & - & $5,00-8,00$ & SNI-03-1968-1990 \\
\hline
\end{tabular}

Sumber : Olahan Data (2020) 
Ivan Setiawan, Suhendra dan Ria Zulfiati, Perbandingan Peningkatan Kuat Tekan Beton Normal Dengan Menggunakan SNI 03-2834-2000 dan SNI 7656:2012 Sampai Umur 28 Hari

\section{Komposisi Campuran}

Rancangan campuran beton normal f'c 25 MPa bagi tiap-tiap SNI dikerjakan berdasarkan menggunakan parameter material yang serupa sesuai hasil sebelumnya.Diperoleh rancangan komposisi campuran beton (mix design) menggunakan SNI 2000 dan SNI 2012 ditunjukan sesuai tabell yaitu :

Tabel 6 Penyusunan bahan per $\mathrm{m}^{3}$ beton

\begin{tabular}{|c|c|c|c|}
\hline \multicolumn{4}{|c|}{ Tabel 6 Penyusunan bahan per $\mathrm{m}^{3}$ beton } \\
\hline \multicolumn{2}{|c|}{ Parameter } & \multicolumn{2}{|c|}{ Macam beton } \\
\hline & & SNI 2000 & SNI 2012 \\
\hline \multirow{5}{*}{$\begin{array}{l}\text { Berat material per } \\
\text { volume } 1 \mathrm{~m}^{3}\end{array}$} & Semen $(\mathrm{kg})$ & 370 & 418,37 \\
\hline & Pasir (kg) & 662,48 & 833,52 \\
\hline & Kerikil (kg) & 1152,52 & 833,9 \\
\hline & Air $(\mathrm{kg})$ & 185 & 205 \\
\hline & Jumlah (kg) & 2370 & 2290,79 \\
\hline
\end{tabular}

Sumber : Olahan Data (2020)

\section{Penyiapan dan Perawatan Benda Uji}

Pencampuran memakai molen laboratorium berukuran mini tipe drum.Benda uji dicor memakai cetakan silinder baja standar dimensi 150 milimeter x 300 milimeter berjumlah 5 benda uji pada tiap-tiap jenis beton. Pemampatan dikerjakan pakai batang penumbuk sesuai 3 lapisan, yang tiap-tiap lapisan dirojok sejumlah 25 kali. ketika berusia 4 jam, permukaan benda uji dikasih lapisan kaping pasta semen biar rata serta halus. Ketika usia benda uji sampai 24 hour, cetakan baja dicopot, selanjutkan dilaksanakan pemulihan memakai teknik perendaman ketika di air mengikuti suhu ruangan sepanjang 28 day.

\section{Prosudur uji tekan}

Percobaan mutu menggunakan mesin mutu tekan hidrololik. percobaan ini dilaksanakan disaat usia benda uji 28 day. Percobaan mutu dikerjakan berdasarkan pedoman SNI 03-1974-1990.

\section{Hasil dan Pembahasan Perbandingan Umum Hasil Rancangan}

Sesuai tata cara rancangan campuran beton bisa dibedakan sebagian ulasan, adalah:

1. Metode pada SNI 2000 sangat komprehensif untuk melihat ikatan empiris jumlah semen, jumlah air serta jumlah agregat, berbeda dengan SNI 2012 sangat simpel dan praktis.

2. Bagi rancangan campuran yang gak memakai syarat deviasi berdasarkan pengujian dahulu, SNI 2000 menghasilkan nilai margin (m) sekuat 12, berbeda dengan SNI 2012 menghasilkan nilai margin (m) sekuat 8,3 (nilai berikut dimaksudkan sesuai SNI 2847:2013). Menurut Tabel 5, didapat sesuai reaksi uji mutu yang diperoleh dari kedua SNI memenuhi kuat tekan rata-rata perlu (f'cr) dan juga mutu diwajibkan (f'c) sesuai yang diinginkan.

3. Diperoleh perhitungan campuran menggunakan SNI 2000 menyatakan jumlah semen, jumlah pasir, serta jumlah air lebih besar dari pada SNI 2012.

\section{Perbandingan Berat Isi Beton}

Pengujian berat isi beton untuk memeriksa perbandingan volume beton yang dilaksanakan dari pengadukan dengan volume beton berdasarkan perencanaan

Tabel 7 Berat Isi Beton

\begin{tabular}{l}
\hline Metode Metode \\
Umur SNI 03-2834-2000 SNI 7656:2012 \\
$\left(\right.$ Hari) $\left(\mathrm{kg} / \mathrm{m}^{3}\right)\left(\mathrm{kg} / \mathrm{m}^{3}\right)$ \\
\hline $32337,332354,67$ \\
$72372,332357,33$ \\
$142376,002287,00$ \\
$212380,002334,33$ \\
$282360,672326,67$ \\
Berat Isi $2365.272332,00$ \\
\hline
\end{tabular}

Sumber : Olahan Data (2020) 
Ivan Setiawan, Suhendra dan Ria Zulfiati, Perbandingan Peningkatan Kuat Tekan Beton Normal Dengan Menggunakan SNI 03-2834-2000 dan SNI 7656:2012 Sampai Umur 28 Hari

Berat isi pada umur 3 hari menunjukan berat isi SNI 7656:2012 lebih besar dari pada SNI 03-2834-2000, Bobot isi di umur 7 day, 14 day, 21 day, 28 day menujukan bahwa lebih besar SNI 03-2834-2000 dibanding pada SNI 7656:2012 dan Bobot isi rata - rata lebih besar SNI 03-2834-2000 dari pada SNI 7656:2012

\section{Perbandingan Tinggi Slump Campuran}

Penskalaan slump dikerjakan dengan kerucut Abram.Percobaan ini dibuat supaya melihat kekentalan (konsistensi dan kohesi) dan kesederhanaan kerja (workability) dari larutan beton basah yang diperlihatkan dengan taksir slump.Reaksi penilaian tinggi slump bagi tiap-tiap macam beton yaitu :

\begin{tabular}{cccc}
\multicolumn{3}{c}{ Tabel 8 Tinggi Slump Campuran } \\
\cline { 2 - 4 } No & Jenis metode campuran beton & Rerata tinggi slump(mm) \\
\hline 1 & SNI 03-2834-2000, 25 MPa & $60-180$ \\
2 & SNI 7656:2012, 25 MPa & $75-100$ \\
\hline
\end{tabular}

Sumber : Olahan Data (2020)

\section{Perbandingan Kuat Tekan Beton}

Tabel 9 mutu masing-masing rancangan campuran

\begin{tabular}{l} 
Rancangan Campuran Beton \\
Umur Metode Metode \\
(Hari) SNI 03-2834-2000 SNI 7656:2012 \\
(MPa) (MPa) \\
\hline 3 15,69 19,79 \\
$724,3126,52$ \\
$1429,1028,63$ \\
$2132,4831,48$ \\
28 39,23 34,92 \\
Sumber : Olahan Data (2020)
\end{tabular}

Gambar 2 Grafik Hubungan umur dengan kuat tekan Metode SNI 03-2834-2000 \& SNI7656:2012

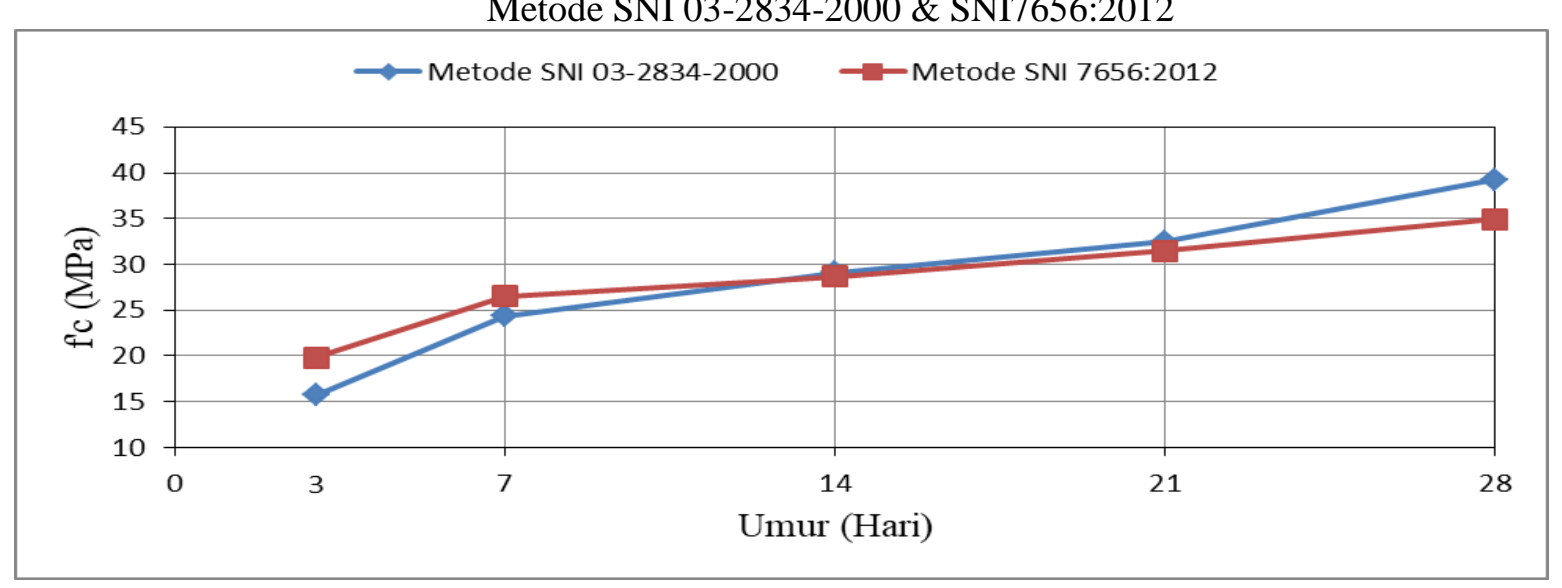

Hasil riset menunjukan untuk usia 3 hari nilai mutu rata-rata dengan memakai rancangan campuran metode SNI 03- 2834-2000 sebesar 15,69 MPa dan rancangan campuran metode SNI 7656:2012 sebesar 19,79 MPa, pada usia 7 hari nilai mutu rata-rata dengan memakai rancangan campuran metode SNI 03-2834-2000 sebesar 24,31 MPa dan rancangan campuran memakai metode SNI 7656:2012 sebesar 26,52 MPa, pada usia 14 hari nilai kuat tekan rata-rata dengan menggunakan rancangan campuran metode SNI 03-2834-2000 sebesar 29,10 MPa dan rancangan campuran menggunakan metode SNI 7656:2012 sebesar 28,63 MPa, pada usia 21 hari nilai kuat tekan rata-rata dengan menggunakan rancangan campuran metode SNI 03-2834-2000 sejumlah 32,48 MPa dan rancangan campuran metode SNI 7656:2012 sebesar 31,48 MPa dan pada usia 28 hari nilai mutu rata-rata dengan menggunakan rancangan campuran metode SNI 03-2834-2000 sebesar 39,23 MPa dan rancangan campuran metode SNI 7656:2012 sebesar $19,79 \mathrm{MPa}$ 


\section{SIMPULAN}

Berdasarkan riset yang diamati, dapat dipelajari sebagai berikut :

1. Terdapat perbedaan mutu tekan rata-rata yang ditargetkan untuk mutu rencana yang sama dikedua metode rancangan campuran beton. Kuat tekan rata-rata yang ditargetkan untuk mutu rencana $25 \mathrm{MPa}$

2. Hasil mutu tekan benda uji umur 28 hari untuk masing-masing metodenya melebihi f'cr

3. Berat isi Beton Rata-rata yang diperoleh menunjukan bahwa metode SNI 03-2834-2000 lebih besar dibanding dengan metode SNI 7656:2012 dikarenakan jumlah kebutuhan material yang diperlukan dalam rancangan campuran beton metode SNI 03-2834-2000 lebih banyak dari metode SNI 7656:2012

4. Pengujian Kuat tekan diumur 3 hari, 7 hari, menggunakan rancangan campuran metode SNI 03-2834-2000 dengan hasil 15,69 MPa dan 24,31 MPa lebih kecil dari pada rancangan campuran menggunakan metode SNI 7656:2012 sebesar 19,79 MPa dan 26,52 MPa dan pada umur 14 hari, 21 day dan 28 day rancangan campuran memakai Metode SNI 03-2834-2000 dengan hasil 29,10 MPa 32,48 MPa dan 39,23 MPa lebih besar dari pada rancangan campuran menggunakan metode SNI 7656:2012 sebesar 28,63 MPa, 31,48 MPa dan 34,92 MPa.

5. Kenaikan nilai mutu rata-rata usia 3 day, 7 day, 14 day, 21 day,28 day dengan memakai SNI 03-2834-2000 berturut-turut sebesar $40 \%, 62 \%, 74 \%, 83 \%, 100 \%$ terhadap usia 28 day, sedangkan kenaikan nilai mutu rata rata SNI 7656:2012 berturut-turut sebesar 57\%, 76\%, 82\%, 90\%, 100\% terhadap usia 28 day. hal ini menunjukan bahwa perkembangan kenaikan mutu pada metode SNI 7656:2012 lebih progresif dibanding metode SNI 03-28342000.

\section{Saran}

Pada riset ini membandingkan rancangan beton pada mutu 25 MPa menggunakan SNI 03-2834-2000 dan SNI 7656:2012 sifat mekanis mutu beton saja Selanjutnya dalam penelitian selanjutnya agar menggunakan kombinasi nilai slump dan variasi mutu beton rencana yang berbeda

\section{DAFTAR PUSTAKA}

ACI Committee 213R-79. (1979). Guide for structural Lightweight Aggregate Concrete, ACI Manual of Concrete Practice.

Nugraha, Paul. (2007). Teknologi Beton. Yogyakarta: Andi Offset.

ASTM C.33 - 02a, "Standard Spesification for Concrete Aggregates", Annual Books of ASTM Standards ,USA

Badan Standardisasi Nasional. (2000). Tata Cara Pembuatan Rencana Campuran Beton Normal. SNI 03-2834-2000. Jakarta: Depertamen Pekerjaan Umum.

Badan Standardisasi Nasional. (2012). Tata Cara Pemilihan Campuran untuk Beton Normal, Beton Berat dan Beton Massal. SNI 7656:2012. Jakarta: Depertamen Pekerjaan Umum.

Badan Standardisasi Nasional. (2011). Cara Uji Kuat Tekan Beton dengan Benda Uji. SNI 1974:2011. Jakarta: Depertamen Pekerjaan Umum

Mulyono, Tri. (2005). Teknologi Beton. Yogyakarta: Andi offset.

Mulyono, Tri. (2006). Teknologi Beton II. Yogyakarta: Andi.

Tjokrodimuljo, Kardiyono. (2004). Teknologi Beton. Yogyakarta: Nafiri. 